LA-UR-01-1812

Approved for public release; distribution is unlimited.

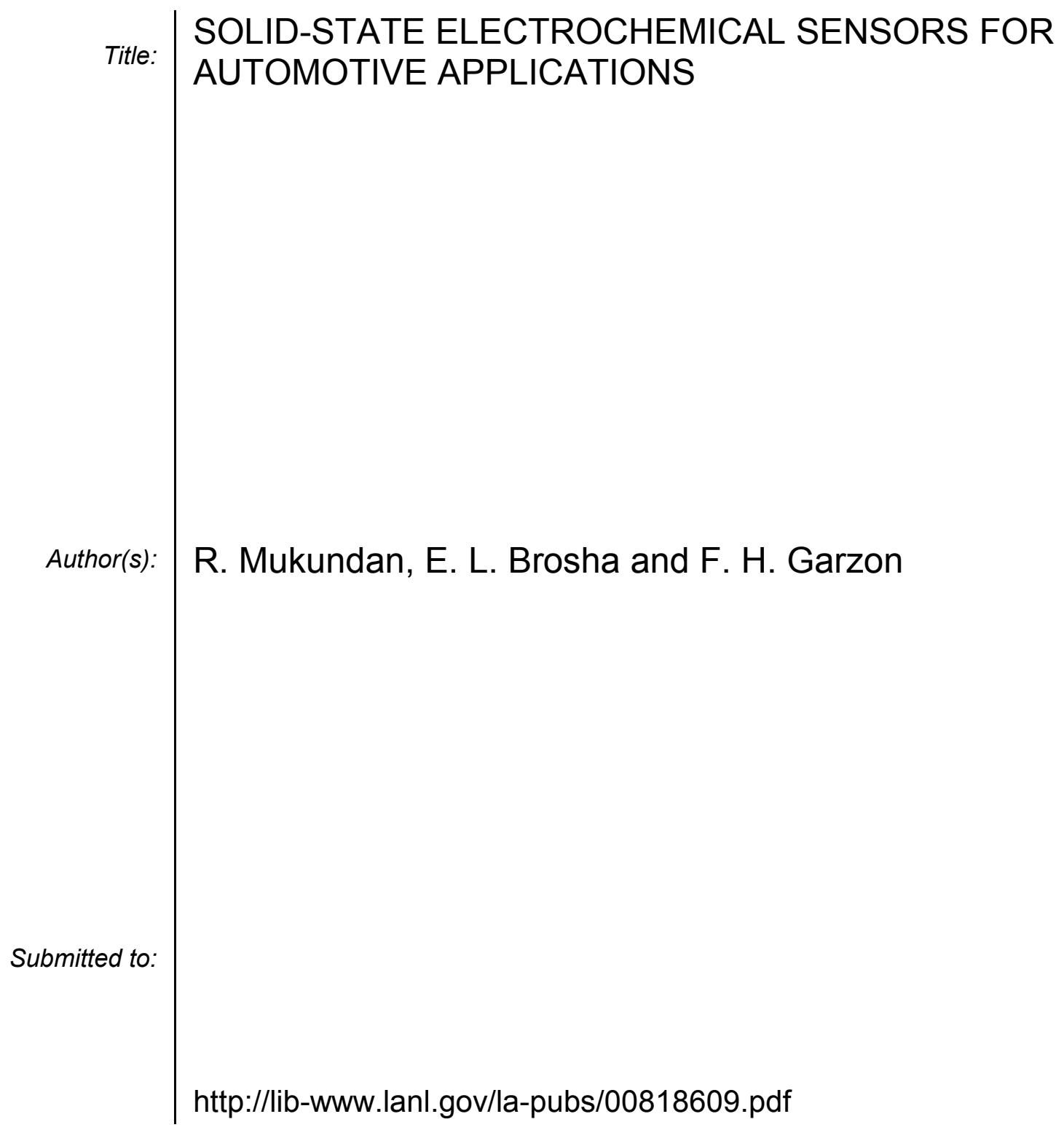

Los Alamos National Laboratory, an affirmative action/equal opportunity employer, is operated by the University of California for the U.S. Department of Energy under contract W-7405-ENG-36. By acceptance of this article, the publisher recognizes that the U.S. Government retains a nonexclusive, royaltyfree license to publish or reproduce the published form of this contribution, or to allow others to do so, for U.S. Government purposes. Los Alamos National Laboratory requests that the publisher identify this article as work performed under the auspices of the U.S. Department of Energy. Los Alamos National Laboratory strongly supports academic freedom and a researcher's right to publish; as an institution, however, the Laboratory does not endorse the viewpoint of a publication or guarantee its technical correctness. 


\title{
SOLID-STATE ELECTROCHEMICAL SENSORS FOR AUTOMOTIVE APPLICATIONS
}

\author{
R. Mukundan, E. L. Brosha and F. H. Garzon \\ Los Alamos National Laboratory \\ MS D429, SM-40, TA-3 \\ MST -11 \\ Los Alamos \\ NM 87545
}

\begin{abstract}
Several types of electrochemical sensors have been studied for application in an automobile. The most prevalent amongst these is the zirconia oxygen sensor, which is also known as the $\lambda$-sensor or Exhaust Gas Oxygen (EGO) sensor. This sensor is used to monitor the oxygen partial pressure in the exhaust, which in turn is utilized to control the air/fuel ratio to the engine. Currently, two such oxygen sensors are being used to determine the "state-of-health" of the catalyst. One sensor is placed upstream of the catalyst and another downstream, and the catalyst efficiency is indirectly monitored by measuring its' oxygen storage capacity. However such a system has several disadvantages and works only when the engine is operated around stoichiometry. There is increasing interest in developing a hydrocarbon sensor that can be used directly to measure the amount of non-methane hydrocarbons (NMHC) in the exhaust stream. The results of a newly developed mixed-potential sensor using platinum $(\mathrm{Pt})$ and $\mathrm{La}_{0.8} \mathrm{Sr}_{0.2} \mathrm{CrO}_{3^{-}}$ oxide (LSCO) electrodes on a $8 \mathrm{~m} \%$ yttria stabilized zirconia (YSZ) electrolyte are presented and its potential application as an automotive NMHC sensor is discussed. This sensor has a response of $40 \mathrm{mV}$ to $500 \mathrm{ppm}$ of propylene at $773 \mathrm{~K}$ in $1 \% \mathrm{O}_{2}$ while the response to the same amount of $\mathrm{CO}$ is only $2 \mathrm{mV}$.

\section{INTRODUCTION}

Tailpipe emissions from automobiles are under increasing scrutiny of the Environmental Protection Agency (EPA) and California Air Resource Board (CARB). California exhaust emission standards for all 2001 model year passenger cars mandates that the non methane organic gasses (NMOG) coming out of the tailpipe of Tier 1 and LEV vehicles be less than 0.25 and $0.075 \mathrm{~g} / \mathrm{mile}$ $\left(1.55 \times 10^{-4}\right.$ and $\left.4.66 \times 10^{-5} \mathrm{~g} / \mathrm{m}\right)$ respectively. Moreover the EPA and CARB also
\end{abstract}


require manufacturers to comply with On-Board Diagnostic (OBD-II) requirements, which mandate that the automobile user be warned by a Malfunction Indicator Light (MIL) when the tailpipe emissions increase by 0.4 $\mathrm{g} / \mathrm{mile}\left(2.5 \times 10^{-4} \mathrm{~g} / \mathrm{m}\right)$. These requirements are currently being met by the dual EGO sensor technology. ${ }^{1,2}$

The dual EGO sensor consists of two Heated-EGO (HEGO) sensors, one placed up-stream of the catalyst and the other down-stream. The up-stream sensor monitors the oxygen partial pressure in the exhaust gases before the catalytic convertor and is used to adjust the Air/Fuel (A/F) ratio to the engine. If the engine is run around stoichiometry, then this sensor displays a step-like response when the $\mathrm{A} / \mathrm{F}$ ratio changes from rich to lean and vice-versa. ${ }^{3}$ However, the response of the second sensor (down-stream of the catalyst) is either delayed and/or dampened due to the oxygen storage capacity of the convertor. The precious metals and the ceria-washcoat in the catalyst have a tendency to store oxygen, which is consumed during hydrocarbon (HC) oxidation and replenished during nitrogen oxide (NOx) reduction. This oxygen storage capacity (OSC) can be linked to the $\mathrm{HC}$ conversion efficiency of the catalyst and is found to have a step like relationship where the OSC decreases dramatically when the $\mathrm{HC}$ conversion efficiency drops from around $95 \%$ to $80 \%$. Therefore the ratio of the two sensor responses can be used as an indirect measure of the hydrocarbon conversion efficiency of the catalyst. ${ }^{1,2}$

Although this dual oxygen sensor approach has worked successfully, there are several disadvantages to this dual EGO sensor approach because it is not a direct measure of the $\mathrm{HC}$ conversion efficiency of the catalyst. The ratio of the responses of the two HEGO sensors is very sensitive to the HC conversion efficiency when the efficiency is $>80 \%$. However, this measure is insensitive when the $\mathrm{HC}$ conversion efficiency drops below $70 \% .{ }^{1}$ Hence this method tends to classify catalysts that are working at $60-75 \%$ efficiency as "failed catalysts". Moreover, in order for this technology to work, the engine should be operated in the closed loop fuel control mode that results in the oscillations of the $\mathrm{A} / \mathrm{F}$ ratio around stoichiometry. These problems can be greatly alleviated by the development of a sensor that would directly measure the $\mathrm{HC}$ content before and after the catalyst.

One such technology that has the potential to measure HCs in a background of $\mathrm{O}_{2}, \mathrm{~N}_{2}, \mathrm{H}_{2} \mathrm{O}, \mathrm{CO}_{2}, \mathrm{CO}$ and NOx is the mixed-potential sensor. ${ }^{4,5}$ Mixed potential sensors have been used in the past for the detection of $\mathrm{CO}^{6,7}, \mathrm{NOx}^{8}, \mathrm{H}_{2}{ }^{9}$ and HCs. ${ }^{10}$ These sensors rely on the fact that two dissimilar electrodes on an oxygen-ion conducting electrolyte exhibit different non-equilibrium potentials in the presence of a reducing gas and oxygen. The potential at any one electrode is fixed by the rate of electrochemical oxidation of the reducing gas $(\mathrm{CO}, \mathrm{HC}$ 's or $\mathrm{NO}_{2}$ ) and the rate of electrochemical reduction of oxygen (Eqns. $1 \& 2$ ). ${ }^{4}$ 


$$
\begin{gathered}
\frac{1}{2} \mathrm{O}_{2}+V_{o}+2 e^{\prime} \leftrightarrow O_{O} \\
C O+O_{O} \leftrightarrow \mathrm{CO}_{2}+V_{o}^{\ddot{\prime}}+2 e^{\prime}
\end{gathered}
$$

The factors that determine the mixed-potential at an electrode/electrolyte interface include; the electrode material, electrode surface-area, 3-phase interface length, amount of reducing gas and oxygen present, flow rates of the gases, and temperature of the measurement. ${ }^{11}$ The working principle of a mixed potential sensor operating at $773-873 \mathrm{~K}$ in a $1 \% \mathrm{O}_{2}$ stream with $0-500 \mathrm{ppm}$ of reducing gas was recently illustrated using a four electrode " $\mathrm{Pt} / \mathrm{Ce}_{0.8} \mathrm{Gd}_{0.2} \mathrm{O}_{1.9} / \mathrm{Au}$ " sensor consisting of $\mathrm{Pt}$ and $\mathrm{Au}$ sensing electrodes and 2 corresponding $\mathrm{Pt}$ reference electrodes. ${ }^{12}$ It was found that the steady state current was determined primarily by the amount of electrochemical oxidation of the reducing-gas while the voltage was determined primarily by the oxygen reduction kinetics of the Au electrode. The response of this sensor to various gases is illustrated in Figure 1 while the stability of response of the individual $\mathrm{Au}$ and $\mathrm{Pt}$ electrodes is represented in Figure 2. ${ }^{12}$ Figure 1 shows that the Au electrode has very little selectivity to HCs relative to $\mathrm{CO}$ and $\mathrm{H}_{2}$. Moreover, from Figure 2 it is clear that the mixed potential is primarily at the Au electrode while the Pt electrode acts like a psedoreference electrode and the stability of the Au electrode is less than desirable.

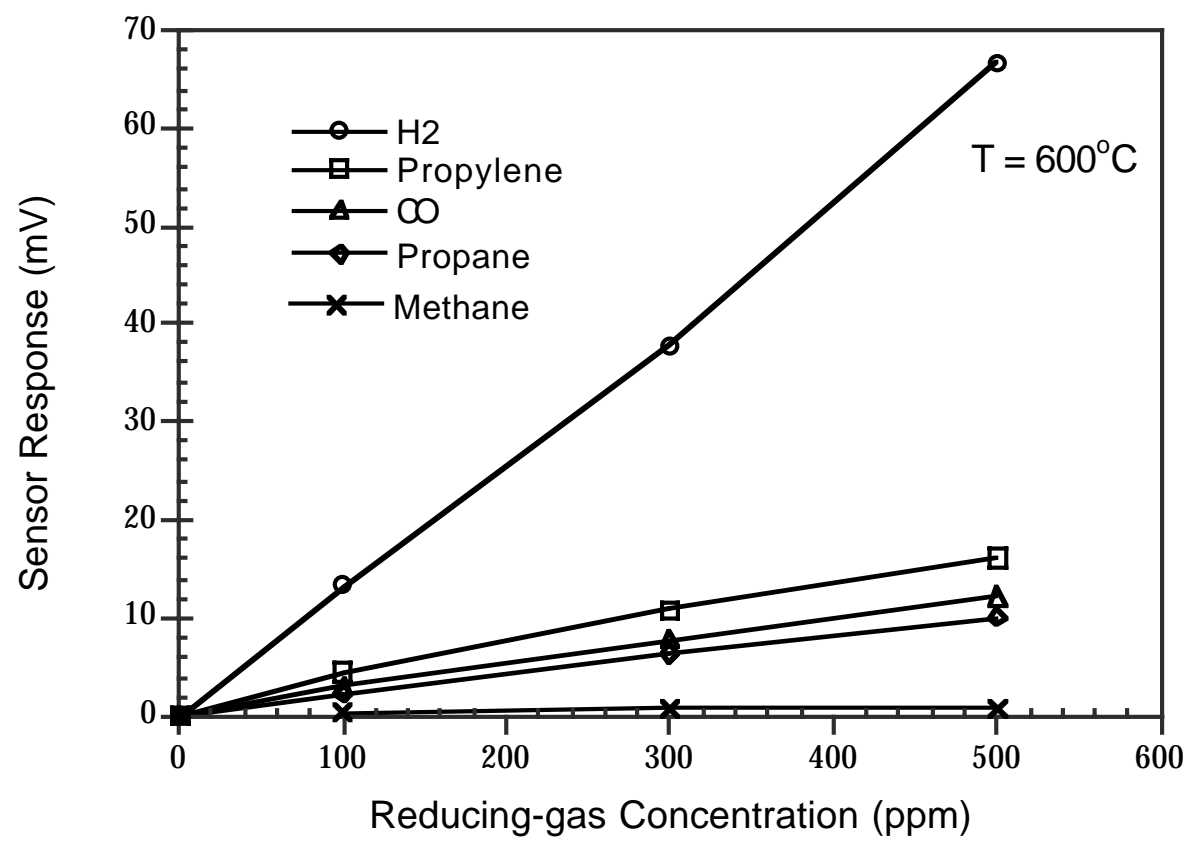

Figure 1. Response of a " $\mathrm{Pt} / \mathrm{Ce}_{0.8} \mathrm{Gd}_{0.2} \mathrm{O}_{1.9} / \mathrm{Au}$ " sensor to various reducing-gases at $873 \mathrm{~K}$. Reproduced by permission of The Electrochemical Society, Inc. ${ }^{12}$ 


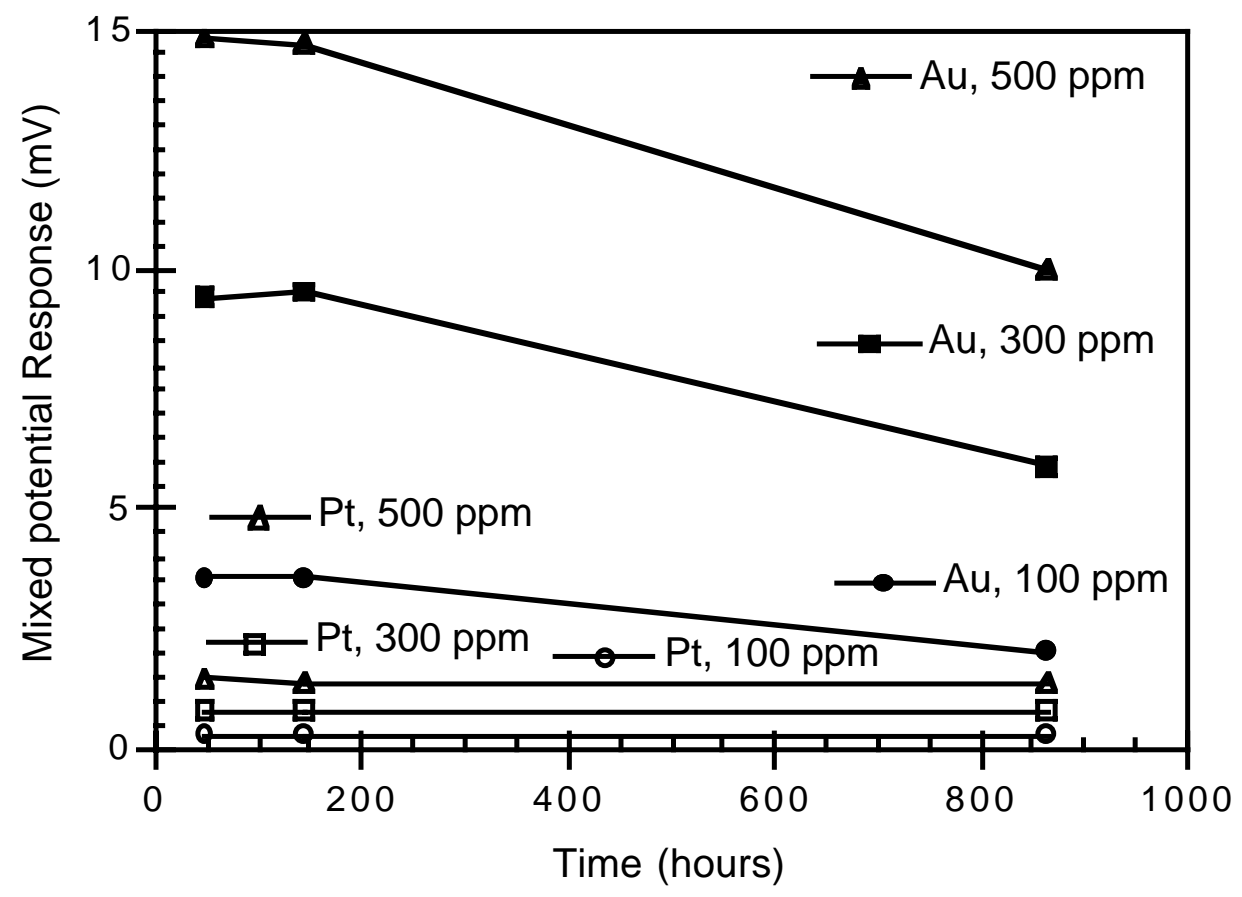

Figure 2. Stability of the gold and platinum electrode potentials to $\mathrm{CO}$ in a $1 \% \mathrm{O}_{2}$ stream at $873 \mathrm{~K}$. Reproduced by permission of The Electrochemical Society, Inc. ${ }^{12}$

Recently, there have been several publications trying to address these limitations by replacing the $\mathrm{Au}$ electrode with an oxide or composite electrode. The electrode materials that have been reported include $\mathrm{Au}-10 \% \mathrm{Ta}_{2} \mathrm{O}_{5}{ }^{10}, \mathrm{In}_{2} \mathrm{O}_{3}$ $0.1 \% \mathrm{MnO}_{2},{ }^{13}$ and $\mathrm{CdO} .{ }^{14}$ In this paper we report the response of a $\mathrm{La}_{0.8} \mathrm{Sr}_{0.2} \mathrm{CrO}_{3}$ (LSCO) electrode on a YSZ electrolyte.

\section{EXPERIMENTAL}

The sensor consists of a LSCO electrode, a Pt electrode and a YSZ electrolyte. The LSCO electrode was prepared from $\mathrm{La}_{0.8} \mathrm{Sr}_{0.2} \mathrm{CrO}_{3}$ powders from Praxair ${ }^{\circledR}$. The powders were first uniaxially pressed in a $1.9 \mathrm{~cm}$ die at $15 \mathrm{Mpa}$ for $300 \mathrm{~s}$ and then isostatically pressed at $200 \mathrm{MPa}$ for $300 \mathrm{~s}$. The LSCO samples were then sintered at $1923 \mathrm{~K}$ for $36000 \mathrm{~s}$ and pellets of approximately $2 \times 2 \times 2 \mathrm{~mm}^{3}$ were cut from this ceramic to be used as the LSCO electrode. A LSCO pellet and a Pt wire (dia. $=0.25 \mathrm{~mm}$ ) were then placed on a $1.9 \mathrm{~cm}$ die and covered with $3 \mathrm{gms}$ of YSZ powder. This was then pressed at $23 \mathrm{Mpa}$ for $300 \mathrm{~s}$ and the resulting sensor assembly was sintered at $1273 \mathrm{~K}$ for $36000 \mathrm{~s} .{ }^{15}$ Two identical sensors (sensor \#1 and sensor \#2) were prepared using the above technique. 
The sensor was then mounted on an alumina rod with Pt leads which was then placed in a quartz tube and heated in a furnace to the operating temperature. The flow rates of the various gas mixtures were controlled using automatic MKS mass flow controllers while the voltage from the sensor was monitored using a Keithly 2400 Source Measure Unit (SMU). The data acquisition was performed using Labview ${ }^{\circledR}$ software running on an Apple ${ }^{\circledR}$ computer. The base gas used was $1 \% \mathrm{O}_{2} / \mathrm{N}_{2}$ which was flown at $3-5 \times 10^{-3} \mathrm{~L} / \mathrm{s}$ over the sample. The mix gases used were $2500 \mathrm{ppm}$ Propylene/ $\mathrm{N}_{2}, 2500 \mathrm{ppm} \mathrm{CO} / \mathrm{N}_{2}, 2500 \mathrm{ppm}$ Propane $/ \mathrm{N}_{2}, 1000$ ppm $\mathrm{H}_{2} / \mathrm{N}_{2}$, and $2500 \mathrm{ppm}$ Methane/ $\mathrm{N}_{2}$. The flow rate of the mix gas was adjusted so as to give the appropriate concentration of the sensing gas in the test mixture.

\section{RESULTS AND DISCUSSIONS}

The response of the two sensors to varying concentrations of propylene in a base gas of $3.3 \times 10^{-3} \mathrm{~L} / \mathrm{s}(200 \mathrm{cc} / \mathrm{min})$ of $1 \% \mathrm{O}_{2} / \mathrm{N}_{2}$ is shown in Figure 3. The initial response of sensor \#1 was much lower than that of sensor \#2. However, when both sensors were annealed at $1073 \mathrm{~K}$ for $3600 \mathrm{~s}$, their responses were almost identical. Moreover, it is seen from Figure 3 that there is no change in the response of sensor $\# 2$ to the annealing process. The Pt electrodes of sensor $\# 2$ (unlike sensor \#1) were cleaned before they were incorporated into the sensor, indicating that the annealing process cleans up the surfaces of the electrodes from

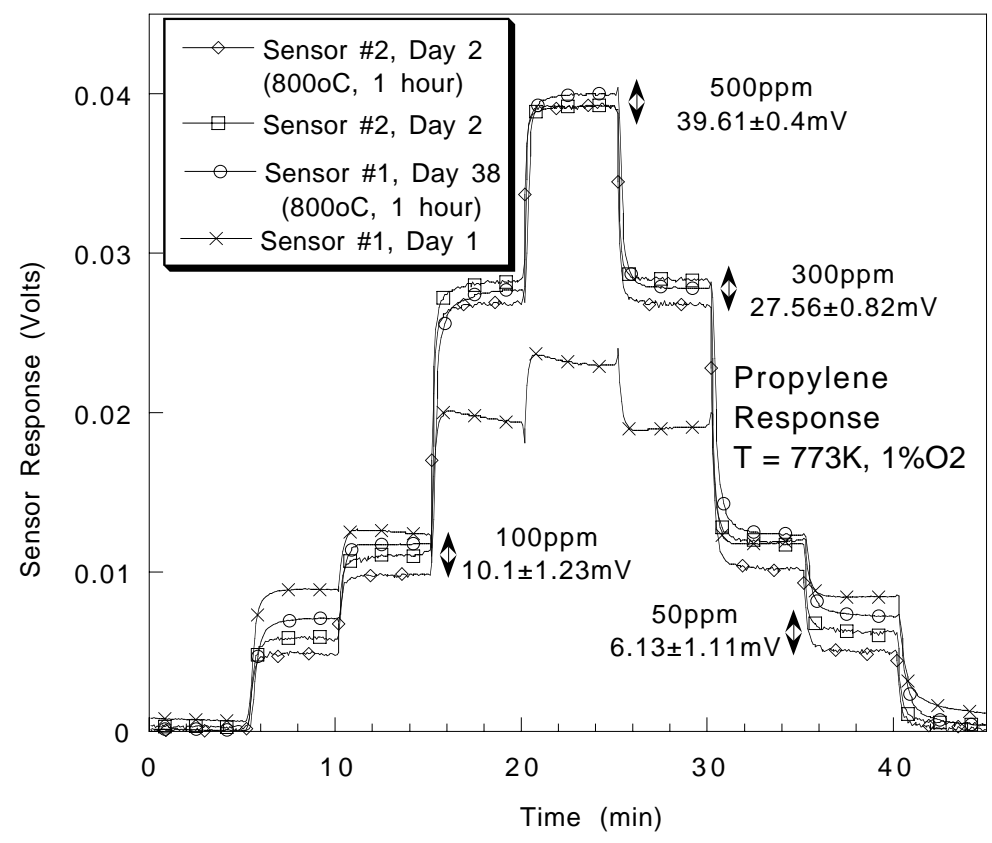

Figure 3. Response of Sensor \#1 and \#2 to varying concentrations of propylene in a $1 \% \mathrm{O}_{2}$ background at $\mathrm{T}=773 \mathrm{~K}$. 


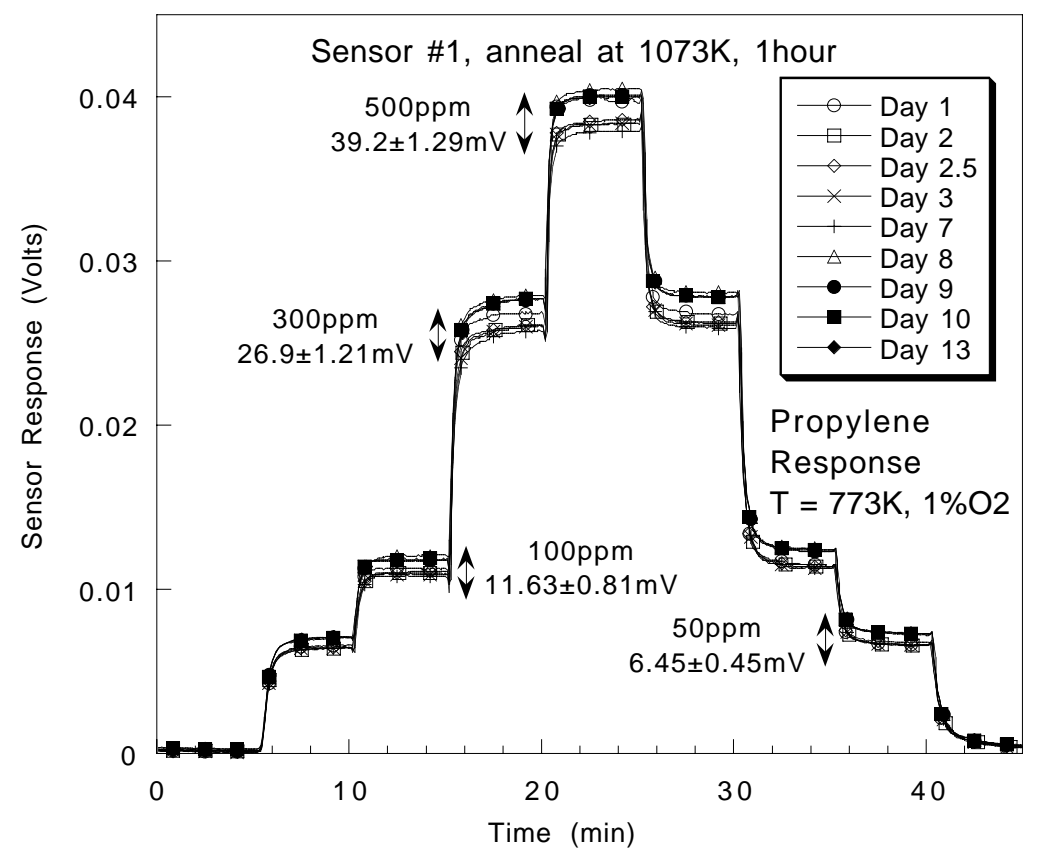

Figure 4. Stability of the response of sensor \#1 to varying concentrations of propylene in a $1 \% \mathrm{O}_{2}$ base gas at $773 \mathrm{~K}$.

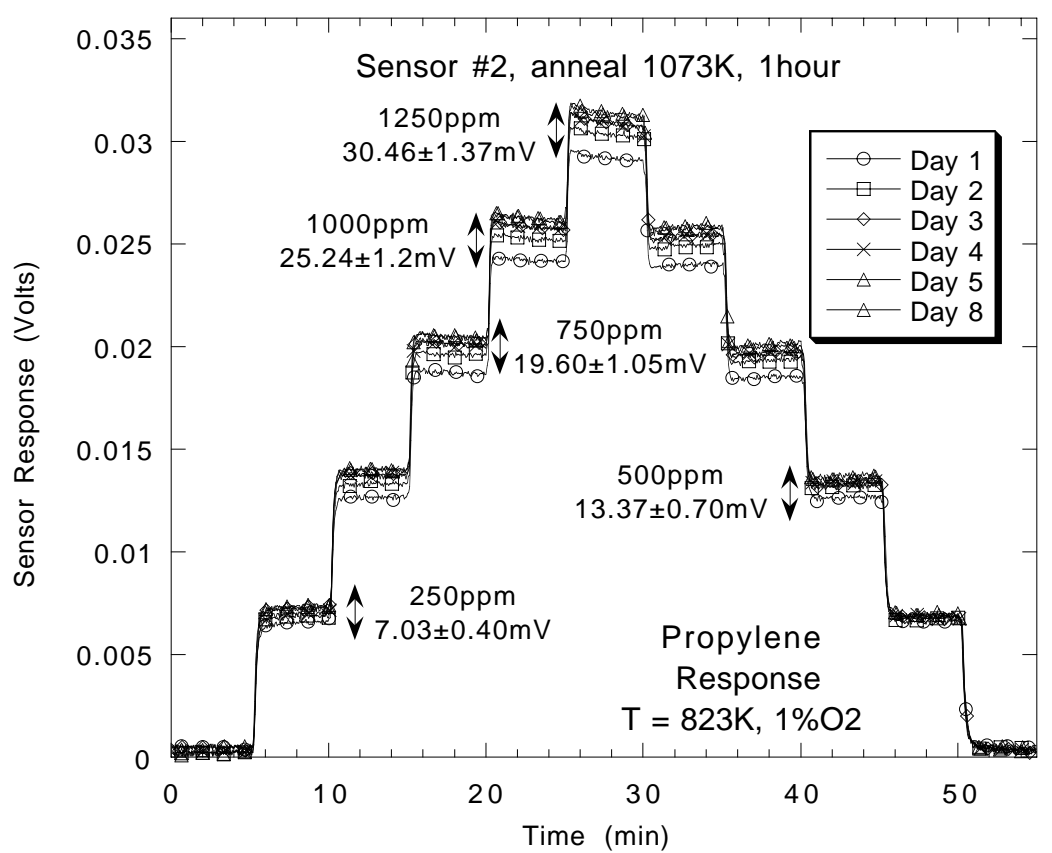

Figure 5. Stability of the response of sensor \#2 to varying concentrations of propylene in a $1 \% \mathrm{O}_{2}$ base gas at $823 \mathrm{~K}$. 
any adsorbed contaminants. The sensor to sensor reproducibility of these two sensors was within $20 \%$ for $50 \mathrm{ppm}$ of propylene and within $1 \%$ for $500 \mathrm{ppm}$ of propylene. This reproducibility is attributed to the precise control of the electrode morphology achieved by using a ceramic pellet instead of a sputtered or paintedon gold electrode. ${ }^{16,17}$

Figures 4 and 5 illustrate the stability of the propylene response of sensor \#1 and $\# 2$ at $773 \mathrm{~K}$ and $823 \mathrm{~K}$ respectively. The response curves indicate that these sensors are very stable at both these temperatures for up to 10 days. The stability of these sensors is a result of the stable morphology of the ceramic-pellet electrode, which does not coarsen with time. This is in contrast to the stability of the Au electrode (Figure 2) whose morphology does change with time due to the re-crystallization of the Au film. ${ }^{12}$

The response time to $90 \%$ of signal level of these sensors is $<25$ s at $823 \mathrm{~K}$ and $<35 \mathrm{~s}$ at $773 \mathrm{~K}$. Although the data points were taken every $2-4 \mathrm{~s}$, only $5 \%$ of the data points are shown in the figures for clarity. The response time of these sensors is expected to be a function of the kinetics of the oxidation and reduction reactions (Eqns. $1 \& 2$ ) occurring at the two electrodes. However the specific factors that control the kinetics of these reactions are not clearly understood at this time and need to be addressed in detail.

Figure 6 illustrates the response of sensor $\# 2$ to various gases at $823 \mathrm{~K}$. In this experiment the base gas $\left(1 \% \mathrm{O}_{2} / \mathrm{N}_{2}\right)$ flow was kept constant at $3.3 \times 10^{-3} \mathrm{~L} / \mathrm{s}$ $(200 \mathrm{cc} / \mathrm{min})$ and the mix gas (containing no oxygen) flow was slowly increased from $3.7 \times 10^{-4} \mathrm{~L} / \mathrm{s}$ to $3.3 \times 10^{-3} \mathrm{~L} / \mathrm{s}$. Hence the oxygen partial pressure is not

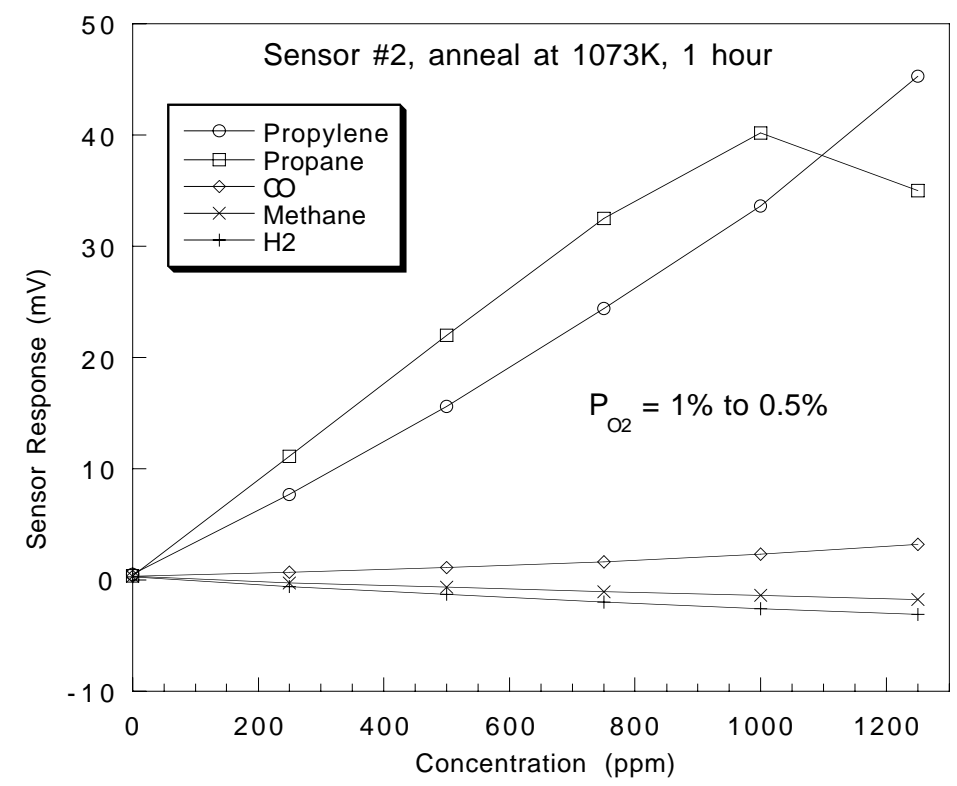

Figure 6. Response of sensor $\# 2$ to various gases at $823 \mathrm{~K}$. 
constant and varies from $1 \% \mathrm{O}_{2}$ at $0 \mathrm{ppm}$ of mix gas to $0.5 \% \mathrm{O}_{2}$ at $1250 \mathrm{ppm}$ of mix gas. The sensor response has a linear relationship to the concentration of all the gases, while the response to the hydrocarbons (Propylene and Propane) is $\approx 14$ times that of CO. Moreover the sensor has only a slightly negative response to $\mathrm{H}_{2}$ and methane which is probably due to a small mixed-potential on the "pseudoreference" platinum electrode. This is in contrast to the gold-electrode-based sensor, which has almost no selectivity towards the hydrocarbons (Figure 1).

It is worth mentioning that in Figure 6, the data point for $1250 \mathrm{ppm}$ of propane does not lie on the linear response curve but is actually lower than the response for $1000 \mathrm{ppm}$ of propane. As mentioned earlier, the oxygen concentration was not kept constant in this experiment and for this particular data point was at $0.5 \% \mathrm{O}_{2}$. Hence when $1250 \mathrm{ppm}$ of propane is present alongside $5000 \mathrm{ppm}$ of $\mathrm{O}_{2}$, we have (see equation 3 ) crossed over from the lean side to the rich side of stoichiometry.

$$
\mathrm{C}_{3} \mathrm{H}_{8}+5 \mathrm{O}_{2} \rightarrow 3 \mathrm{CO}_{2}+4 \mathrm{H}_{2} \mathrm{O}
$$

Hence these sensors have a linear response curve to the concentration of reducinggas only in the presence of excess oxygen. Thus these sensors can be operated only on the lean side of stoichiometry and probably would not work for an engine that is running fuel rich.

\section{CONCLUSIONS}

The newly fabricated "LSCO/YSZ/Pt" sensor has several desirable characteristics that could be utilized in an on-board hydrocarbon sensor for monitoring automobile tailpipe emissions. The sensor has good selectivity to hydrocarbons and excellent stability and reproducibility. The long-term stability of these sensors and their ability to withstand the hash conditions in an automobile exhaust needs to be examined. However, these can be expected to be reasonably good considering the stability of the individual components used. The YSZ electrolyte is currently being used in the EGO sensor and the platinum electrode should be at least as stable as the platinum used in the catalytic convertor. Moreover, the other electrode (LSCO) is currently being considered as an interconnect material in solid oxide fuel cells and is known to withstand high temperatures (up to $1273 \mathrm{~K}$ ) and huge swings in the partial pressure of oxygen. However, the response time $(<25 \mathrm{~s}$ to $90 \%$ of response at $823 \mathrm{~K})$ and sensitivity $\left(\approx 2.5 \mu \mathrm{V} /\right.$ ppm of propylene at $823 \mathrm{~K}$ and $\left.1 \% \mathrm{O}_{2}\right)$ of this device are still major impediments to the practical application of these sensors.

\section{ACKNOWLEDGEMENTS}


This work was funded by USCAR DOE CRADA 94-MULT0912-E5-2. Los Alamos National Laboratory is operated by the University of California for the U.S. Department of Energy under contract W-7405-ENG-36.

\section{REFERENCES}

${ }^{1}$ J.S. Hepburn, D.A. Dobson, C.P. Hubbard, S.O. Guldberg, E. Thanasiu, W.L. Watkins, B.D. Burns and H.S. Gandi, "A Review of the Dual EGO Sensor Method for OBD-II Catalyst Efficiency Monitoring," SAE Transactions, 103 [4] paper 942057 1866-1909 (1994).

${ }^{2}$ W.B. Clemmens, M.A. Sabourin and T. Rao, "Detection of Catalyst Performance Loss Using On-Board Diagnostics," SAE Transactions, 99 [4] paper 900062 1866-1909 (1990).

${ }^{3}$ E.M. Logothetis, "ZrO2 Oxygen Sensors in Automotive Applications"; pp. 388-405 in Advances in Ceramics, Volume 3. Edited by A.H. Heuer and L.W. Hobbs. The American Ceramic Society, Inc. Ohio (1981).

${ }^{4}$ D. E. Williams, P. McGeehin and B. C. Tofield, "Solid Electrolyte Mixed Potential Phenomenon"; pp. 275-278 in Proc. of the Second European Conf., Solid State Chemistry. Edited by R. Metselaar, H.J.M. Heijligers and J. Schoonman. Elsevier Publishing Company, Amsterdam (1983).

${ }^{5}$ R. Mukundan, E.L. Brosha, D.R. Brown and F.H. Garzon, "CeriaElectrolyte-Based Mixed Potential Sensors for the Detection of Hydrocarbons and Carbon Monoxide," Electrochemical and Solid-State Letters, 2 [8] 412-414 (1999).

${ }^{6}$ N. Miura, T. Raisen, G. Lu and N. Yamazoe, "Highly Selective CO Sensor Using Stabilized Zirconia and a Couple of Oxide Electrodes," Sensors and Actuators, B47 84-91 (1998).

${ }^{7}$ R. Sorita and T. Kawano, "A Highly Selective CO Sensor using LaMnO3 Electrode-attached Zirconia Galvanic Cell," Sensors and Actuators, B40 29-32 (1997).

${ }^{8}$ N. Miura, G. Lu, N. Yamazoe, H. Kurosawa and M. Hasei, "Mixed Potential Type $\mathrm{NO}_{\mathrm{x}}$ Sensor Based on Stabilized Zirconia and Oxide Electrode," $J$. Electrochem. Soc., 143 [2] L33-L35 (1996).

${ }^{9}$ G. Lu, N. Miura and N. Yamazoe, "High Temperature Hydrogen Sensor Based on Stabilized Zirconia and a Metal Oxide Electrode," Sensors and Actuators, B35-36 130-135 (1996).

${ }^{10}$ T. Hibino, S. Kakimoto and M. Sano, "Non-Nernstian Behavior at Modified Au Electrodes for Hydrocarbon Gas Sensing," J. Electrochem. Soc., 146 [9] 33613366 (1999).

${ }^{11}$ F.H Garzon, R. Mukundan and E.L. Brosha, "Mixed Potential Sensors: Theory, Experiments and Challenges," Solid State Ionics, 136 633-638 (2000). 
${ }^{12}$ R. Mukundan, E.L. Brosha, D.R. Brown and F.H. Garzon, "A MixedPotential Sensor Based on $\mathrm{Ce}_{0.8} \mathrm{Gd}_{0.2} \mathrm{O}_{1.9}$ electrolyte and Platinum and Gold Electrodes," J. Electrochem. Soc., 147 [4] 1583-1588 (2000).

${ }^{13}$ T. Hibino, S. Tanimoto, S. Kakimoto and M. Sano, "High-Temperature Hydrocarbon Sensors Based on a Stabilized Zirconia Electrolyte and Metal Oxide Electrodes," Electrochemical and Solid-State Letters, 2 [12] 651-653 (1999).

${ }^{14}$ N. Miura, T. Shiraishi, K. Shimanoe and N. Yamazoe, "Mixed-potentialtype propylene sensor based on stabilized zirconia and oxide electrode," Electrochemistry Communications, 2 77-80 (2000).

${ }^{15}$ R. Mukundan, E.L. Brosha and F. Garzon, US Patent, Serial \# 09/770,928, applied on January 252001.

${ }^{16}$ E.L. Brosha, R. Mukundan, D.R. Brown, F.H. Garzon, J.H. Visser, M. Zanini, Z. Zhou and E.M. Logothetis, "CO/HC sensors based on thin films of $\mathrm{LaCoO}_{3}$ and $\mathrm{La}_{0.8} \mathrm{Sr}_{0.2} \mathrm{CoO}_{3-\delta}$ metal oxides," Sensors and Actuators, B69 171-182 (2000).

${ }^{17}$ R. Mukundan, E.L. Brosha and F. Garzon, US Patent, Serial \# 09/770,359, applied on January 252001. 